CAHIERS DE

NARRATOLOGIE

\section{Cahiers de Narratologie}

Analyse et théorie narratives

32 | 2017

Récit et argumentation, interactions, lieux et dispositifs sociaux

\title{
Edwige Comoy Fusaro, Poliorama. Le immagini di
}

Carlo Dossi

Serge Lorenzo Milan

\section{CpenEdition}

Journals

Electronic version

URL: http://journals.openedition.org/narratologie/7879

DOI: $10.4000 /$ narratologie. 7879

ISSN: 1765-307X

Publisher

LIRCES

Electronic reference

Serge Lorenzo Milan, «Edwige Comoy Fusaro, Poliorama. Le immagini di Carlo Dossi », Cahiers de Narratologie [Online], 32 | 2017, Online since 21 December 2017, connection on 25 September 2020 URL : http://journals.openedition.org/narratologie/7879; DOI : https://doi.org/10.4000/narratologie. 7879

This text was automatically generated on 25 September 2020.

Article L.111-1 du Code de la propriété intellectuelle. 


\title{
Edwige Comoy Fusaro, Poliorama. Le immagini di Carlo Dossi
}

\author{
Serge Lorenzo Milan
}

\section{REFERENCES}

EDWIGE COMOY fuSARo, Poliorama. Le immagini di Carlo Dossi, «Chemins it@liques », Neuville sur Saône, Éditions Chemins de tr@verse, 2015, 394 pages, $36 €$

1 Cette étude a pour objet l'œuvre littéraire de Carlo Dossi (1849-1910), examinée au travers de l'une de ses figures de style de prédilection, l'image, dans ses variantes rhétoriques et sémantiques les plus significatives. Pourtant, presque deux ans après sa publication remarquée, et par-delà les travaux littéraires des spécialistes de cet auteur et de cette période dont elle constitue désormais une référence essentielle, ce sont les analyses et les questionnements même de l'image comme stylème, comme fonction et comme structure qui retiennent au moins autant l'attention du lecteur.

2 On sait que Alberto Carlo Pisani Dossi est un écrivain rattaché au courant des Scapigliati (« les échevelés »), mouvement littéraire et artistique original lombard, proto décadent et avant-gardiste, pour autant que ces catégories puissent désigner des phénomènes équivalents dans deux pays européens aussi différents, socialement et culturellement, que la France et l'Italie de la seconde moitié du XIX ${ }^{e}$ siècle. Toutefois, alors que ses camarades écrivains comme Tarchetti ou Praga menaient une vie de bohême et parfois de misère, cet aristocrate dandy s'engagea dans les cabinets ministériels et les Affaires Etrangères du nouveau Royaume d'Italie, et cessa pratiquement d'écrire après 1880 pour se consacrer presque exclusivement à sa carrière, ainsi qu'à l'archéologie (à l'exception toutefois notable des Amori, sorte d'adieu littéraire publié en 1887).

3 Poliorama, d'après le néologisme forgé par Dossi pour qualifier ses «fantaisie philosophiques ", parcourt et contextualise ainsi la production littéraire de cet auteur depuis ses œuvres de jeunesse jusqu'à La desinenza in A. Ritratti umani (1878) - son œuvre la plus estimée -, en examinant les caractères figuratifs et la typologie de son 
imaginaire. L'ouvrage, dont les quatre parties sont complétées par un appareil critique et une bibliographie très complète, propose en son premier chapitre une réflexion sur l'imagination de Dossi, sa rhétorique et la sémantique de ses images, analogies ou métaphores ; le deuxième chapitre est consacré à sa veine satirique, liée à des figures d'occultation et de dévoilement ainsi qu'à la présence récurrente dans ses œuvres de voix narratives subtilement dédoublées ; les troisième et quatrième chapitres, aux analyses particulièrement fines et approfondies, sont consacrés aux images dossiennes liées respectivement à la nourriture et à l'enfance, mettant par ailleurs l'accent d'une part sur un parcours créatif et philosophique restitué avec grande clarté, et d'autre part sur une langue expérimentale à la fois contestataire et démiurgique, dans sa remarquable idiosyncrasie histrionique.

4 Cependant, depuis sa redécouverte au milieu des années 1990 - notamment grâce à la réédition de ses œuvres par Dante Isella et une monographie de Antonio Saccone -, le statut littéraire de Dossi ne se limite plus à une réputation d'excentricité linguistique : ses pastiches stylistiques, souvent fragmentaires, ont notamment attiré l'attention de chercheurs comme Francesca Caputo ou, en France, la regrettée Pérette-Cécile Buffaria, qui en avaient déjà souligné l'humour égotique et méta-narratif.

De ce point de vue, l'apport essentiel du travail d'Edwige Comoy Fusaro, qui explore un domaine jusque-là négligé, est la thèse que l'écriture de Dossi est, contrairement à celles autres Scapigliati, essentiellement «animée par la joie, plutôt que par la douleur", au sein d'une tradition épicurienne et immanentiste retraçable dans ce dédoublement des narrateurs en alter ego problématiques, ainsi que dans l'élaboration d'un imaginaire enfantin transfiguré par la multiplication d'images domestiques, corporelles, alimentaires et solaires, que l'on a pu rattacher à la rusticité d'une ligne «lombarde» avec Dante Isella ou Alberto Arbasino, mais qui est ici ramenée pertinemment à sa dimension rabelaisienne, après une analyse serrée de leur profusion enivrante très concrète, prégnante, souvent ironique et comique.

6 C'est ce travail synchronique sur l'image, et sur ses variantes formelles et fonctionnelles, qui donne à cette étude une ampleur qui dépasse largement le cadre strict de l'analyse monographique, par ailleurs si brillamment honorée. Il s'agit en effet du premier travail sur Dossi à se concentrer sur cet aspect fondamental de l'écrivain, pourtant si excessivement visuel et métaphorique, où l'image elle-même finit par faire question : "qu'est-ce exactement qu'une image ?", se demande très tôt l'auteure, et cette interrogation s'impose comme le fil rouge d'une lecture alors toujours plus prenante, philosophique s'il en est.

7 Représentations et analogies, simulacres et signes, doubles et désirs, enfin amorces de séquences narratives et de récits mythiques par leur accumulation et leur agencement polysémique, les images dossiennes illustrent de façon exemplaire à la fois la double veine de leur auteur - alternant sans cesse et circulairement la satire, voire la polémique antibourgeoise, avec une cosmogonie liée à l'enfance - mais également la puissance de cette figure rhétorique sans équivalent de par sa nature même, dont Gian Pietro Lucini et l'avant-garde futuriste, avec leurs « chevauchées d'images ", seront en Italie les héritiers les plus directs.

8 C'est dans cette minutieuse analyse des images et de leur nature que l'étude d'Edwige Comoy Fusaro atteint, disions-nous, un domaine qui n'est plus exclusivement celui des spécialistes de la langue et de la littérature italienne. Ainsi et par exemple, si le chapitre sur l'image entre eikon et eidos illustre l'ambiguïté des images de Dossi, 
toujours entre représentation et narration, il rappelle surtout le statut d'une figure de rhétorique qui, loin d'être aux antipodes de la conceptualisation, en est la racine même, participant d'une cosmogonie et d'une connaissance du monde plus ancienne et enfouie - selon une intuition, une théorisation et une pratique qui furent par ailleurs celles de son quasi contemporain Nietzsche, comme le soulignaient déjà Clément Rosset et Sarah Kofman.

\section{AUTHOR}

\section{SERGE LORENZO MILAN}

LIRCES EA 3159, Université Côte d'Azur 